\title{
O Uso de Redes Neurais Artificiais para Análise da Presencialidade em um Fórum LV
}

\author{
Francisco Aislan da Silva Freitas ${ }^{1}$, Monck Charles Nunes de Albuquerque ${ }^{1}$, \\ Gilvandenys Leite Sales ${ }^{1}$, Cláudio Marques de Sá Medeiros ${ }^{1}$, \\ Antônio Leandro Martins Cândido ${ }^{1}$, Pedro Pedrosa Rebouças Filho ${ }^{1}$ \\ ${ }^{1}$ Programa de Pós-Graduação em Ciência da Computação - PPGCC \\ Instituto Federal de Educação, Ciência e Tecnologia do Ceará - IFCE \\ Av. Treze de Maio, 2081 - Benfica - 60.040-215 - Fortaleza - CE - Brazil \\ \{aislansf, monckena, denyssales, claudiosa1965, \\ www. leocandido, pedrosarf\} @gmail.com
}

\begin{abstract}
This paper has a proposal to select students from a Discussion Forum based on the management of an Artificial Neural Network (RNA). A Multi Layer Perceptron RNA (MLP) was applied to a database extracted from AVA Moodle forums that use the LV Evaluation Model.
\end{abstract}

Resumo. Este artigo apresenta uma proposta de classificação dos alunos de um Fórum de discussão com base na presencialidade utilizando uma Rede Neural Artificial (RNA). Foi aplicada a RNA Multi Layer Perceptron (MLP) em uma base de dados extraída de fóruns do AVA Moodle que utilizam o Modelo LV de avaliação.

\section{Introdução}

As redes sociais, a internet e seu aparato tecnológico apresentam avanços que envolvem cada vez mais seus usuários. Essa ideia de permanecer conectado fez nascer um novo hábito: o de sentimento de pertencimento a um grupo [Bastos et al. 2011]. Nesta abordagem, a presencialidade social caracteriza-se com as diversas formas que as pessoas interagem por meios de recursos tecnológicos. Estudar e analisar esse hábito, tem se tornado complexo entre aqueles que se interessam por Tecnologias Digitais da Informação e Comunicação (TDIC) e o apoio à aprendizagem.

Os pesquisadores Kim et al. (2016), Bizzo (2009), Silva (2012) e Valente (2000) vem averiguando a presencialidade dos discentes em Ambientes Virtuais de Aprendizagem (AVA) e declaram que essa presencialidade é importante para o processo de ensino e aprendizagem. Albuquerque et al. (2018), apresentam uma proposta de solução, para encontrar o Fator Presencialidade dos discentes em um fórum LV de discussão. Em seu trabalho foi aplicado lógica fuzzy para identificar o nível de presencialidade dos discentes participantes. Nos últimos anos, pesquisadores como de Melo et al. (2006) e Barbosa (2007) têm utilizado as redes neurais artificias para treinar, testar e implantar uma solução para as diversas situações que são encontradas em AVAs. de Melo et al. (2006) apresenta um sistema de tutoria inteligente, baseado em redes neurais artificiais Multi Layer Perceptron (MLP, do português Perceptron Multi Camadas), provido de característica adaptativa e reativa, proporcionando um ensino personalizado e dinâmico. Este artigo apresenta uma proposta de avaliação da Presença Social em ambientes virtuais. 
VII Congresso Brasileiro de Informática na Educação (CBIE 2018)

Anais do XXIX Simpósio Brasileiro de Informática na Educação (SBIE 2018)

\section{Redes Neurais Artificiais}

Redes Neurais Artificiais (RNAs) são modelos de processamento que tem como princípio imitar a atividade de processamento do cérebro humano. A rede MLP é o modelo mais frequente na literatura. A rede MLP é composta por neurônios e os mesmos são divididos em camadas (Entrada, Oculta e Saída). O poder computacional da MLP é derivado da capacidade de manipular dados não linearmente separáveis e pela habilidade de aprender com a experiência, através de treinamentos supervisionados. Neste modelo de aprendizado, normalmente os padrões de entrada são associados a padrões de saída e os algoritmos de treinamento usam essa referência para adequar os valores dos pesos da RNA [Haykin 2001].

\section{Procedimento Metodológico}

O modelo proposto por Albuquerque et al. (2018), o qual utiliza lógica fuzzy para encontrar o fator presencialidade, foi tomado como referência para realização do estudo, assim como o modelo LV de avaliação formativa [Sales 2010]. Foi utilizada a mesma base de dados e interações entre os alunos. Desta forma, seria possível realizar uma comparação dos valores encontrados por meio deste experimento. Foi utilizado uma biblioteca do Spyder ${ }^{\circledR}$, denominada de Sklearn MLPClassifier, para encontrar o fator presencialidade de cada discente no Fórum LV. Para tal fim, foi implementado a Rede Neural Artificial Perceptron Multi Camada, definindo-se os atributos de entrada, a quantidade de neurônios na camada oculta e a quantidade de neurônios na camada de saída (Figura 1).

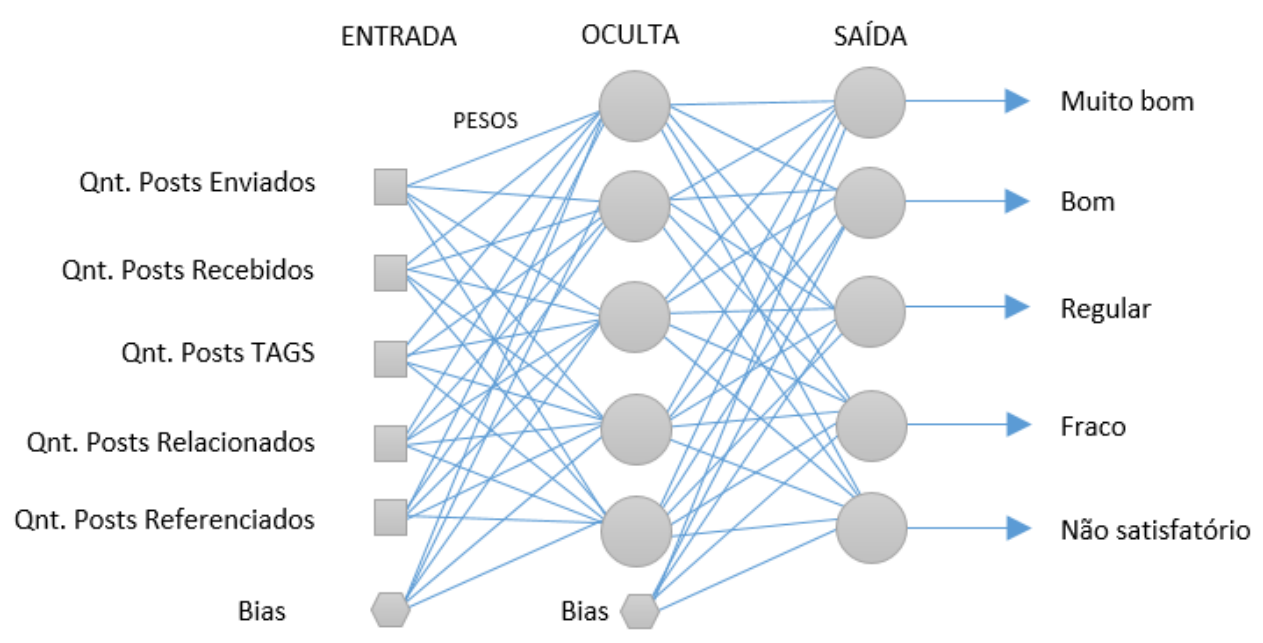

Figura 1. Estrutura da MLP para Avaliar a Presencialidade no Fórum LV.

A base de dados foi dividida em $75 \%$ para treinamento e $25 \%$ para teste, nos dois casos foram utilizadas amostras aleatórias afim de tornar o processo mais robusto. Foram realizados 50 treinamentos em cada topologia. Inicialmente foram utilizados os parâmetros padrão da biblioteca Sklearn MLPClassifier do Spyder ${ }^{\circledR}$ : 5 neurônios na camada oculta, 200 interações, taxa de tolerância de 0.0001 , método de otimização para atualização dos pesos descida do gradiente estocástica, otimizada por Kingma and Ba (2014) denominado por Adam, modo de ativação denominada relu(retorna $\mathrm{f}(\mathrm{x})=\max (0$, $\mathrm{x})$ ), taxa de aprendizagem 0.001 e a taxa de momento de 0.9. 
VII Congresso Brasileiro de Informática na Educação (CBIE 2018)

Anais do XXIX Simpósio Brasileiro de Informática na Educação (SBIE 2018)

Após o treinamento com os parâmetros padrão da biblioteca, foram realizadas alterações nos parâmetros, afim de encontrar a maior taxa de acerto médio, com a menor variância. Sendo assim a configuração a seguir alcançou melhores resultados, comparandoos com as configurações padrão da biblioteca: 5 neurônios na camada oculta, 200 interações, taxa de tolerância de 0.0001 , método de otimização para atualização dos pesos descida do gradiente estocástica, otimizada por Kingma and Ba (2014) denominado por Adam, modo de ativação tangente hiperbólica (tanh), taxa de aprendizagem 0.1 e a taxa de momento de 0.9 .

\section{Conclusão}

Como indicado neste estudo, buscou-se contemplar os modelos utilizados na construção de redes neurais artificiais aplicando a MLP para mensurar a presencialidade de discentes em um Fórum LV. O uso da MLP nos permite realizar diversos treinamentos até encontrar a melhor taxa de acerto, referente à base de dados usada no estudo, sendo possível analisar a participação dos alunos nos AVA.

\section{Referências}

Albuquerque, M., Sales, G. L., Medeiros, C., and Barroso, G. (2018). Mensurando a presencialidade em um fórum ead com lógica fuzzy. In $V C B S F$ - Congresso Brasileiro de Sistemas Fuzzy, volume 5.

Barbosa, Andréa TR e de Azevedo, F. M. (2007). Uma hipermídia educacional: adaptativa através do uso de redes neurais artificiais. In Brazilian Symposium on Computers in Education (Simpósio Brasileiro de Informática na Educação-SBIE), volume 1, pages 113-122.

Bastos, H. P. P., Bercht, M., and Wives, L. K. (2011). Presença social e pertencimento em fóruns educacionais: manifestação e percepção de afetividade. In Brazilian Symposium on Computers in Education (Simpósio Brasileiro de Informática na Educação-SBIE).

de Melo, F. R., Martins, W., Nalini, L. E. G., and Meireles, V. (2006). Generalizador neural de espaços de aprendizagem em sistemas tutores inteligentes. In Brazilian Symposium on Computers in Education (Simpósio Brasileiro de Informática na EducaçãoSBIE), volume 1, pages 141-150.

Haykin, S. (2001). Redes neurais: princípios e prática. Porto Alegre.

Kim, J., Song, H., and Luo, W. (2016). Broadening the understanding of social presence: Implications and contributions to the mediated communication and online education. Computers in Human Behavior, 65:672-679.

Kingma, D. P. and Ba, J. (2014). Adam: A method for stochastic optimization. arXiv preprint arXiv:1412.6980.

Sales, G. L. (2010). Learning vectors (lv): um modelo de avaliação da aprendizagem em ead online aplicando métricas não-lineares. Tese de doutorado, Universidade Federal do Ceará-UFC.

Silva, J. K. K. d. (2012). Automatização do processo de identificação de presença social em fóruns e chats. In Brazilian Symposium on Computers in Education (Simpósio Brasileiro de Informática na Educação-SBIE).

Valente, J. A. (2000). Educação a distância: uma oportunidade para mudança no ensino. Educação a distância no Brasil na era da Internet. São Paulo: Anhembi Morumbi Editora, pages 97-122. 